\title{
Intravenous Thrombolysis for Acute Ischaemic Stroke in Young Adult Patients
}

\author{
Alexandre Y. Poppe, Alastair M. Buchan, Michael D. Hill
}

\begin{abstract}
Background: Intravenous tissue plasminogen activator (IV tPA) has been studied primarily in patients over age 50. We sought to describe baseline differences in adult patients $\leq 50$ years-old taken from a large prospective cohort of acute stroke patients treated with intravenous tPA (IV tPA) and to determine whether outcomes differed for this population. Methods: Data ( $\mathrm{n}=1120$ ) prospectively collected from the Canadian Alteplase for Stroke Effectiveness Study (CASES) were reviewed and patients aged $\leq 50$ years-old $(n=99)$ were compared with those aged $>50$ years $(n=1021)$ with regards to baseline characteristics, symptomatic intracerebral haemorrhage (sICH), functional outcome at 90 days and death. Results: Nine percent of patients were $\leq 50$ years-old. Among patients aged $\leq 50$ years, $40.4 \%$ were women and median age was $42 \pm 6.1$ years (range 20 to 50 ). They had significantly more current cigarette use but fewer other vascular risk factors than older patients $(p<0.05)$ and their baseline median NIHSS score was lower $(13$ versus 15 , $\mathrm{P}=0.001$ ). Although this group was more likely to have a favourable 90 -day outcome, multivariable regression confirmed that age $\leq 50$ years, while independently associated with a decreased risk of death (RR $0.36,95 \%$ CI 0.14 to 0.95 ), was not itself predictive of favourable 90-day outcome or decreased risk of sICH. Conclusions: Adult patients $\leq 50$ years-old had fewer medical co-morbidities and a modestly lower baseline median NIHSS score than their older counterparts. Age $\leq 50$ years was independently associated with a decreased risk of death but not with favourable outcome or risk of sICH.
\end{abstract}

RÉSUMÉ: Thrombolyse intraveineuse dans l'accident vasculaire cérébral aigu ischémique chez les jeunes adultes. Contexte : L'administration intraveineuse de l'activateur du plasminogène tissulaire (rt-PA IV) a été étudiée surtout chez les patients de plus de 50 ans. Notre but était de décrire les caractéristiques de patients adultes de 50 ans et moins faisant partie d'une cohorte prospective importante de patients atteints d'un accident vasculaire cérébral aigu (AVCA) traités par rt-PA IV et de déterminer si le résultat thérapeutique était différent chez ces patients. Méthodes : Nous avons révisé les données recueillies de façon prospective au cours de l'étude Canadian Alteplase for Stroke Effectiveness Study (CASES) sur 1120 patients et nous avons comparé les patients âgés de 50 ans et moins $(\mathrm{n}=99)$ à ceux de plus de 50 ans $(\mathrm{n}=1021)$ quant aux caractéristiques initiales, à l'hémorragie intracérébrale symptomatique (HICs), au résultat fonctionnel après 90 jours et au décès. Résultats : Neuf pour cent des patients étaient âgés de 50 ans et moins. Parmi ces patients, $40,4 \%$ étaient des femmes et l'âge médian était de $42 \pm 6,1$ ans (écart de 20 à 50 ans). Le taux de tabagisme actuel était significativement plus élevé dans ce groupe, mais ces patients présentaient moins d'autres facteurs de risque vasculaire que les patients plus âgés (p < 0,05 ) et leur score médian au NIHSS était plus bas (13 versus $15 ; \mathrm{p}=0,001$ ). Bien que ce groupe soit plus susceptible d'avoir un résultat favorable après 90 jours, l'analyse de régression multivariée a confirmé que l'âge de 50 ans et moins, bien qu'associé de façon indépendante à un risque plus faible de décès (RR 0,36 , IC à $95 \%$ de 0,14 à 0,95 ), n'était par en soi prédictif d'un résultat favorable à 90 jours ou d'un risque plus faible d'HICs. Conclusions : Les patients adultes de 50 ans et moins avaient moins de co-morbidités médicales et un score médian initial NIHSS légèrement plus bas que ceux de plus de 50 ans. Être âgé de 50 ans et moins était associé de façon indépendante à un risque plus faible de décès mais n'était pas associé à une issue favorable ou au risque d'HICs.

Can. J. Neurol. Sci. 2009; 36: 161-167

Although stroke is generally a disease of the elderly, up to $12 \%$ of first strokes occur in young adult patients ${ }^{1,2}$, commonly defined as those aged 50 years or less. Young adults with ischaemic stroke tend to have a more favourable prognosis than older patients, however, their risk of disability and death is significantly higher than that of the general population of the same age $e^{3-7}$. The cost to society is particularly pronounced since these young patients become disabled during their peak years of productivity. Twenty to $50 \%$ of patients are unable to return to work $^{5,8,9}$ and most have a longer lifetime of disability and risk for medical complications than older stroke patients.
From the Calgary Stroke Program (AYP), Department of Clinical Neurosciences / Medicine / Community Health Sciences, Hotchkiss Brain Institute (MDH), University of Calgary, Foothills Medical Centre, Calgary, Alberta, Canada; Nuffield Department of Clinical Medicine (AMB), University of Oxford, John Radcliffe Hospital, Headington, Oxford, United Kingdom.

Received SePtember 24, 2008. Final Revisions Submitted October 31, 2008. Correspondence to: Alexandre Y. Poppe, Calgary Stroke Program, University of Calgary, Foothills Medical Centre, 1403 29th Street NW, Calgary, Alberta, T2N 2T9, Canada. 
Intravenous tissue plasminogen activator (IV tPA) is an accepted standard therapy for acute ischaemic stroke and has been found to decrease long-term disability when given within three hours of symptom-onset ${ }^{10}$. However, its use in stroke has been studied primarily in adults over age 50. A subgroup analysis of the NINDS tPA trial suggested that younger adults benefit more than older patients when adjusted for baseline stroke severity, but the number of patients aged less than 50 in that study was small" ${ }^{\prime \prime}$ Younger patients also face unique challenges with regards to thrombolysis given possible delayed recognition of symptoms, incorrect physician diagnosis and more varied stroke etiologies. Most studies of thrombolysis in ischaemic stroke have not specifically addressed outcome or process issues, such as onset-to-treatment time (OTTT), door-to-CT time, doorto-needle time and frequency of protocol violations in young adult patients $^{12}$.

We therefore sought to describe baseline differences in patients $\leq 50$ years-old taken from a large prospective cohort of acute ischaemic stroke patients treated with IV tPA and to determine whether process issues and outcomes differed for this population.

\section{Methods}

Data prospectively collected in the Canadian Alteplase for Stroke Effectiveness Study (CASES) were analyzed. This was a national prospective cohort study that lead to the full approval of IV-tPA for acute ischemic stroke in Canada and its methodology has been described previously ${ }^{13}$. Sixty sites across the country participated over a period of 2.5 years (2001-2003) and where relevant, each centre obtained institutional ethics approval for data collection. Patients were treated at the discretion of the site neurologist according to Canadian guidelines for intravenous thrombolytic treatment in acute stroke ${ }^{14}$.

Baseline demographic data were obtained as were pretreatment blood tests, data regarding timing of drug administration and stroke subtype as determined by the site investigator using the Oxfordshire Community Stroke Project (OCSP) classification ${ }^{15}$. The severity of the baseline neurological deficit was assessed with the National Institute of Health Stroke Scale (NIHSS) prior to treatment. The outcome was measured using the modified Rankin Scale (mRS) at 90 days by clinicians who were not blinded to patient age. A favourable outcome was defined as a mRS score of 0-1. All patients underwent a follow-up head computed tomography (CT) scan at 24-48 hours.

Baseline and follow-up CT scans were centrally reviewed by a stroke neurologist and neuroradiologist blinded to clinical information, and the Alberta Stroke Program Early CT Score (ASPECTS) was applied ${ }^{16}$. Symptomatic intracerebral haemorrhage $(\mathrm{SICH})$ was defined as any haemorrhage documented on follow-up CT associated with a decline in neurological status within the first $24 \mathrm{~h}$ after thrombolytic treatment as judged by the site investigator, who was not blinded to clinical information. Asymptomatic ICH involved hemorrhage on follow-up CT without associated clinical deterioration.

As a primary analysis, patients were dichomotized into those aged $\leq 50$ years and those older than 50 . Both groups were compared with regard to baseline characteristics, rate of $\mathrm{sICH}$, functional outcome at 90 days, discharge destination, length of hospitalization and death. Multivariable logistic regression was used to identify whether age $\leq 50$ was an independent predictor of outcome. A secondary analysis examined the association of outcome with age as a continuous measure.

The CASES study was funded in part by the Canadian Stroke Consortium, the Canadian Stroke Network, the Heart \& Stroke Foundation of Canada and Hoffmann-La Roche Canada Ltd. None of the sponsors had any role in the collection, analysis or interpretation of the data.

\section{Statistical Analysis}

Fisher's exact test and Student's t test were used to compare the two groups. Both binomial regression and logistic regression were used to develop models for the three outcomes of interest depending upon use. For graphical descriptions, multivariable logistic regression was used. For tabular description of risk ratios, multivariable binomial regression was used to identify predictors of outcome using a log-link function. The final models were all parsimonious models, meaning that variables that were not significant at $\mathrm{p}<0.05$ or variables that showed no evidence of confounding were eliminated from the final models. Models were developed by backwards stepwise elimination. The final models were adjusted for gender, baseline NIHSS score and baseline serum glucose. Analyses were conducted using STATA 8.2 (Statacorp, College Station, TX, USA).

\section{RESULTS}

\section{Baseline characteristics}

Of 1135 patients enrolled in CASES, 1120 had adequate data for inclusion in the current study. Median age was 73 years (range 20 to 97 ), $45 \%$ were women and $96 \%$ had an anterior circulation stroke. The frequency distribution of patient ages is shown in Figure 1. Ninety-nine patients $(8.8 \%)$ were aged $\leq 50$ years. Among these younger patients, $40.4 \%$ were women and median age was $42 \pm 6.1$ years (range 20 to 50 ). They had

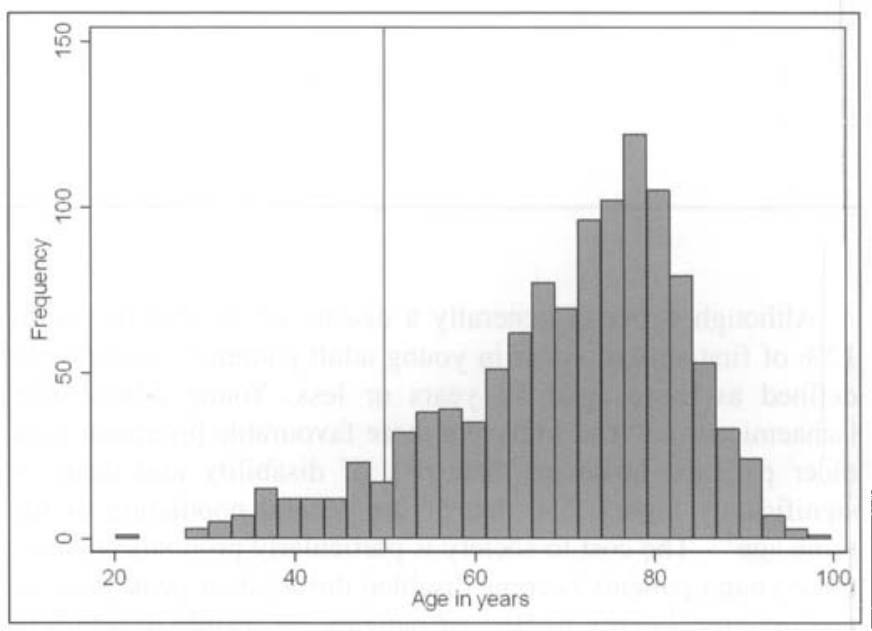

Figure 1: Frequency distribution of patient ages in all patients $(n=1120$; vertical line indicates age 50 ). 
Table 1: Baseline patient characteristics

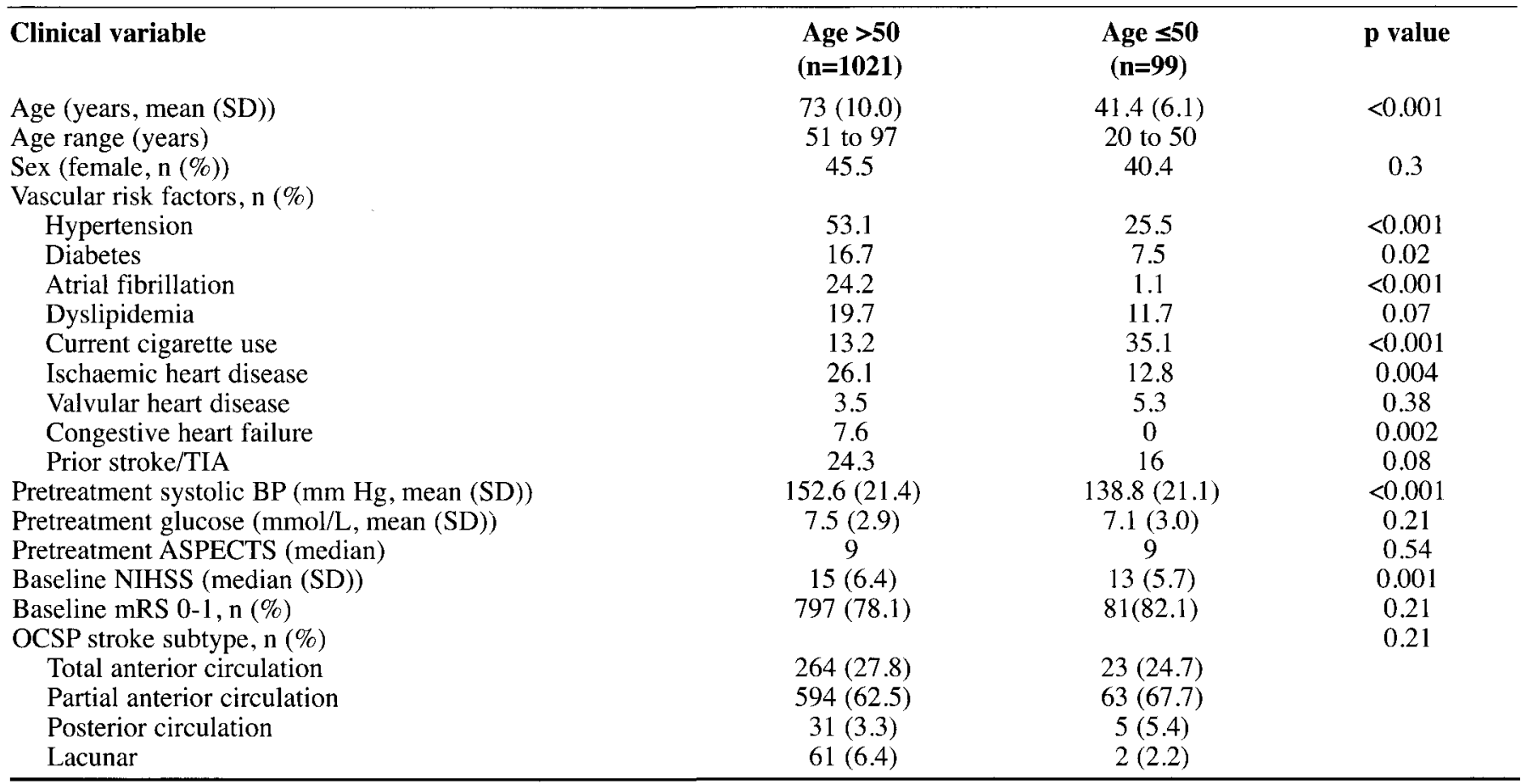

(not all percentages are calculated from the total number of patients because certain clinical variables were not available for all patients). ASPECTS, Alberta Stroke Program Early CT Score; BP, blood pressure; mRS, modified Rankin Scale; NIHSS, National Institutes of Health Stroke Scale; TIA, transient ischaemic attack

Table 2: Comparison of process measures in patients aged $\leq 50$ years and those aged $>50$ years

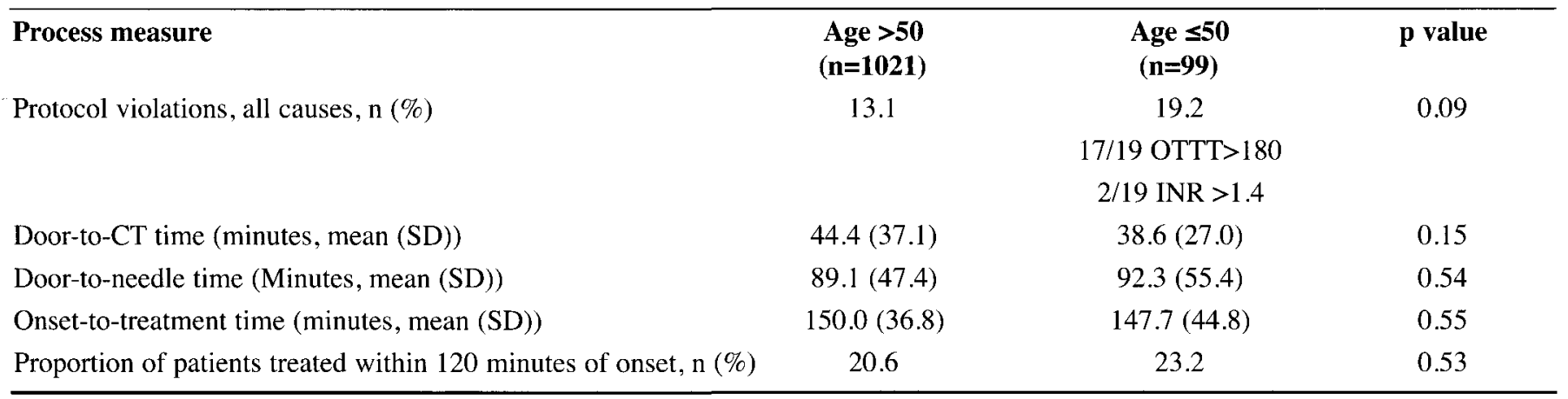

(not all percentages are calculated from the total number of patients because certain clinical variables were not available for all patients) OTTT, onset-to-treatment time; INR, International Normalized Ratio 
significantly more current cigarette use but fewer other vascular risk factors than patients over 50, including hypertension, ischaemic heart disease, atrial fibrillation, congestive heart failure and diabetes mellitus (Table 1). Median pre-treatment systolic blood pressure was also lower among younger patients $(138.8 \pm 21.1$ versus $152.6 \pm 21.4, \mathrm{p}<0.001)$ as was baseline median NIHSS score $(13 \pm 5.7$ versus $15 \pm 6.4, \mathrm{P}=0.001)$. There were no differences in baseline glucose, mRS, ASPECTS or stroke subtype, although there was a non-significant trend suggesting fewer lacunar strokes in the younger group.

\section{Process Issues}

Door-to-CT, door-to-needle and onset-to-treatment time did not differ significantly between the groups (Table 2). The proportion of patients treated within two hours of symptom onset also did not differ between older and younger patients (23.3 versus $20.6 \%, \mathrm{p}=0.53$ ). There was a trend towards a higher percentage of protocol violations among younger patients (19.2\% versus $13.1 \%, \mathrm{p}=0.09)$, and these were primarily comprised of treatment initiation beyond three hours (17 of 19 protocol violations).

\section{Symptomatic ICH,90-day functional outcome, death and other outcomes}

Clinical outcome measures are shown in Table 3. A total of 52 patients $(4.6 \%)$ developed sICH. Among younger patients, this proportion was $3 \%$, which did not differ from a rate of $4.7 \%$ for those over $50(\mathrm{p}=0.62)$. This yielded a risk ratio of $0.51(95 \% \mathrm{CI}$ 0.12 to 2.1 ) after multivariable regression to adjust for potential confounders (Table 4).

Functional outcome and death at 90-days, unadjusted for confounders, are shown in Figure 2. The proportion of younger patients with an excellent outcome was significantly higher than among older patients ( $50 \%$ versus $35.5 \%, \mathrm{p}=0.006$ ). Although this yielded a significant unadjusted risk ratio of $1.41(95 \% \mathrm{CI}$ 1.14 to 1.75 ) for age $\leq 50$, this was rendered non-significant after adjustment for confounding variables $1.24(95 \% \mathrm{CI} 0.85$ to
1.84). Mortality was significantly lower among patients aged $\leq 50(10.2 \%$ versus $23.5 \%, \mathrm{p}=0.002)$, yielding an adjusted risk ratio of 0.40 ( $95 \%$ CI 0.18 to 0.89 ). Multivariable analysis found that baseline NIHSS, baseline CT ASPECTS and admission glucose were independent predictors of 90-day outcome and death. However, age $\leq 50$, while independently associated with a decreased risk of death, was not itself predictive of favourable 90-day outcome or decreased risk of sICH. Because the bulk of poor outcomes among older patients might be driven by those over 80 years-old, analyses were repeated excluding these oldest patients (not shown). Nevertheless, the same relationships between age $\leq 50$ and outcomes persisted.

Younger patients had a significantly shorter median length of hospitalization after their stroke ( 7 versus 11 days, $p=0.002$ ) and a greater proportion of them were discharged directly home after admission ( $49.5 \%$ versus $31.5 \%, \mathrm{p}=0.002)$.

\section{Age as a continuous variable}

Using age as a continuous variable, the probability of an excellent functional outcome at 90-days adjusted for baseline NIHSS score, baseline ASPECTS, admission glucose, OTTT and gender was derived from a linear regression and represented as a linear model (Figure 3). This yielded an inverse relationship between age and the probability of achieving an mRS of $0-1$.

\section{Discussion}

Our study examined baseline characteristics, process issues and outcomes exclusively in young adult patients treated with IV-tPA for stroke. As might be expected, younger patients had fewer vascular co-morbidities and a trend towards fewer prior strokes or transient ischaemic attacks. Their index strokes were also modestly less severe, but baseline level of functioning was the same as their older counterparts. Our results suggest that process issues and tPA-related complications did not differ between younger and older patients. The favourable functional outcome and lower mortality among young adult stroke patients described by others ${ }^{3-7}$, is further confirmed by our data.

Table 3: Symptomatic intracranial hemorrhage and 90-day outcome in patients aged $\leq 50$ years and those aged $>50$ years

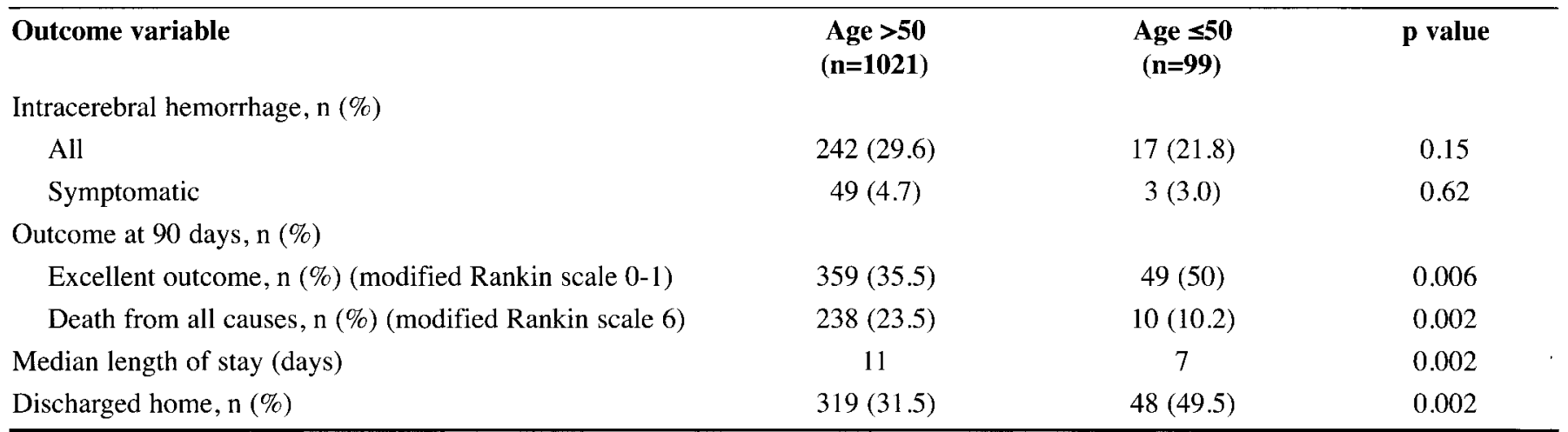

(not all percentages are calculated from the total number of patients because certain clinical variables were not available for all patients) 


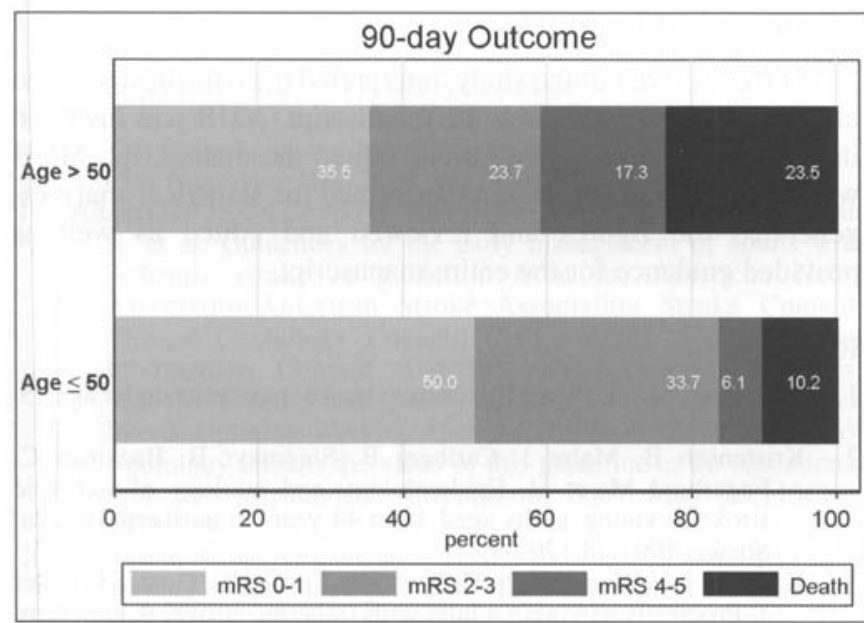

Figure 2: Patient outcome at 90-day follow-up by baseline glucose (unadjusted for other predictors of outcome) mRS, modified Rankin Scale; $m R S 0-1$, excellent outcome; $m R S 2-3$, moderate disability; $m R S$ 4-5, severe disability; $m R S 6$, dead.

However, multivariable regression analysis suggests that young age itself only predicts decreased mortality and not better functional outcome. Younger age might independently predict lower 90-day mortality because of variables not explicitly captured by our study but for which young age might be a surrogate marker. These include fewer non-vascular comorbidities, decreased risk of or improved resiliency to inhospital medical and stroke complications, more aggressive medical care, fewer do-not-resuscitate orders and decreased exposure to the potential medical complications of institutionalized long-term care.

With regards to functional outcome, younger adults with stroke appear to fare better not by virtue of their age alone, but because they enjoy a lower burden of significant medical comorbidities such as diabetes mellitus, atrial fibrillation and ischaemic heart disease, which have been associated with worse outcome after stroke $\mathrm{e}^{7,17}$. Other factors favouring recovery in the young, such as improved brain plasticity ${ }^{18}$ and more robust family and social support can be posited, but were not captured by our study design.

Current guidelines ${ }^{14,19,20}$ do not comment on the use of tPA in young adults versus older patients, although adult patients aged $\leq 50$ represented a minority of those enrolled in the NINDS tPA trial $^{10}$. In that study, only $156(25 \%)$ of patients were 60 yearsold or less and most of these were between 50 and 60 . A post-hoc subgroup analysis of the NINDS tPA study suggested the possibility of greater benefit of tPA in younger patients, when adjusted for stroke severity, but no clear age threshold for benefit was demonstrated"1.

Many potential barriers exist to the timely delivery of thrombolysis for stroke ${ }^{21}$ and it has been hypothesized that young adult stroke patients face unique challenges regarding tPA therapy. These include inadequate consideration of stroke as a cause of symptoms, failure to utilize EMS services ${ }^{22}$, improper exclusion of a stroke diagnosis by emergency room physicians ${ }^{23}$ and more atypical stroke etiologies, including higher rates of cervical artery dissection, which may be less amenable to treatment with $\mathrm{tPA}^{7,24}$.

The lack of differences in onset-to-treatment, door-to-CT and door-to-needle times between younger and older patients suggests that among patients treated with tPA, there were no significant delays in the younger group. However, patients who were not offered treatment due to excessive time delays would not have been captured in the CASES database. Data on specific stroke etiology were also not recorded and therefore conclusions regarding safety of tPA in young patients with specific stroke mechanisms (such as arterial dissection) cannot be drawn. Stroke classification using (OCSP) definitions has been correlated with broad etiologic mechanisms ${ }^{25}$. Nevertheless, apart from a trend towards fewer lacunar strokes among younger patients, more detailed information regarding specific stroke etiologies cannot be reliably inferred from the available data. Also, outcome measures of particular importance in younger patients, such as quality of life and post-stroke depression ${ }^{9}$, were not recorded. Another limitation of the current study is its observational design. However, data were prospectively and rigorously collected from a large number of representative patients drawn from 60 hospitals across Canada.

Younger adults represent a significant proportion of stroke patients and in our cohort, had fewer medical co-morbidities, lower pretreatment blood pressure and a modestly lower baseline

Table 4: Unadjusted and adjusted risk ratios

\begin{tabular}{lcc}
\hline Outcome variable & Risk Ratio (95\% CI) & Adjusted \\
Symptomatic intracerebral hemorrhage & Unadjusted & $0.51(0.12$ to 2.1$)$ \\
Excellent outcome (modified Rankin scale 0-1) & $1.41(1.14$ to 1.75$)$ & $1.24(0.85$ to 1.84$)$ \\
Death from all causes (modified Rankin scale 6) & $0.43(0.24$ to 0.79$)$ & $0.40(0.18$ to 0.89$)$ \\
\hline
\end{tabular}

For symptomatic intracerebral hemorrhage, excellent outcome and death in patients aged $\leq 50$ years versus patients aged $>50$ years. Adjusted for gender, baseline NIHSS score, baseline glucose. 


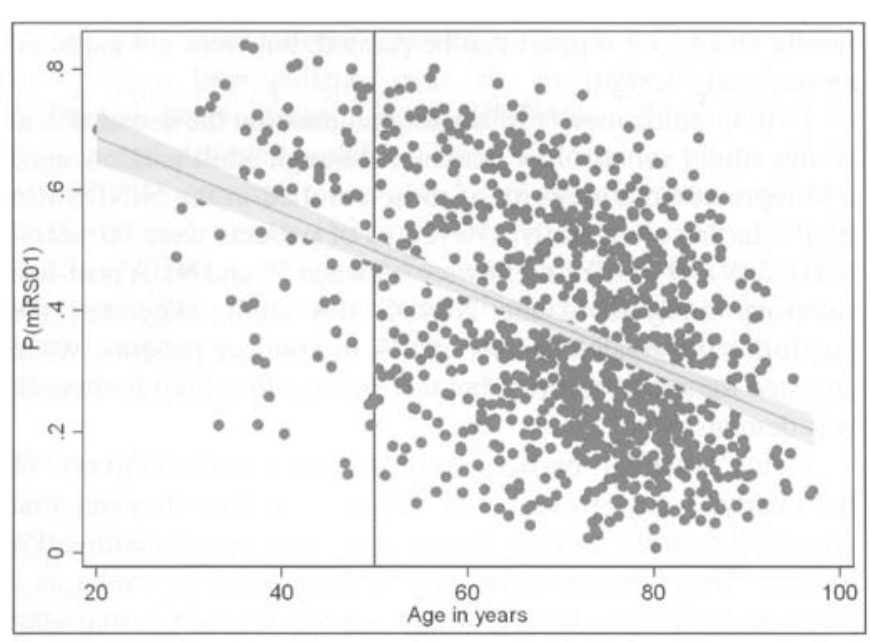

Figure 3: Relationship between age and the probability of an excellent outcome. The line and confidence intervals are derived from a linear regression of age and the predicted probability of excellent outcome adjusted for baseline NIHSS score, baseline ASPECTS, admission glucose, onset-to-treatment time and gender. For each decade older, the probability of an excellent outcome falls by $6.3 \%$.

median NIHSS score than their older counterparts. However, there was a trend towards a higher a rate of protocol violations in these patients, primarily related to treatment beyond three hours. This may reflect a willingness among physicians to be more aggressive when treating young adults. The younger patients had shorter hospitalizations and were more often discharged home from hospital. Nevertheless, half of them could not return directly home after being hospitalized and $10 \%$ died by 90 days. This is similar to the mortality rate found in published cohorts of young stroke patients who were not uniformly thrombolyzed ${ }^{2,7.26-30}$.

As a whole, younger adults experienced more favourable outcomes after treatment with IPA than older patients. However, they did not have lower rates of sICH. Better outcomes in younger patients are not solely attributable to age, but may rather be explained by a lower burden of medical co-morbidities and perhaps other neurophysiological and psychosocial factors that remain to be elucidated.

\section{ACKNOWLEDGEMENTS AND FUNDING}

The study was funded cooperatively by the Canadian Stroke Consortium, the Canadian Stroke Network and Hoffmann-La Roche Canada Ltd. AMB was funded in part by the Alberta Heritage Foundation for Medical Research and the Heart and Stroke Foundation of Alberta, NWT \& Nunavut. MDH received salary support from the Alberta Heritage Foundation for Medical Research and the Heart \& Stroke Foundation of Alberta, NWT and Nunavut.

\section{AUTHOR's CONTRIBUtions}

AYP conceived of the study, interpreted the data, designed the tables and wrote and edited the manuscript. AMB was involved in study design and reviewed and edited the manuscript. MDH was involved in study design, performed the statistical analyses, generated the figures and reviewed and edited as well as provided guidance for the entire manuscript.

\section{REFERENCES}

1. Bogousslavsky J, Pierre P. Ischemic stroke in patients under age 45. Neurol Clin. 1992;10:113-24.

2. Kristensen B, Malm J, Carlberg B, Stegmayr B, Backman C, Fagerlund M, et al. Epidemiology and etiology of ischemic stroke in young adults aged 18 to 44 years in northern Sweden. Stroke. 1997;28:1702-9.

3. Kappelle LJ, Adams HP Jr, Heffner ML, Torner JC, Gomez F, Biller J. Prognosis of young adults with ischemic stroke. A long-term follow-up study assessing recurrent vascular events and functional outcome in the Iowa Registry of Stroke in Young Adults. Stroke. 1994 Jul;25(7):1360-5.

4. Marini C, Totaro R, Carolei A. Long-term prognosis of cerebral ischemia in young adults. National Research Council Study Group on Stroke in the Young. Stroke. 1999 Nov;30(11):2320-5.

5. Varona JF, Bermejo F, Guerra JM, Molina JA. Long-term prognosis of ischemic stroke in young adults. Study of 272 cases. J Neurol. 2004 Dec;251(12):1507-14.

6. Rozenthul-Sorokin N, Ronen R, Tamir A, Geva H, Eldar R. Stroke in the young in Israel: incidence and outcomes. Stroke. 1996;27: $838-41$.

7. Arnold M, Halpern M, Meier N, Fischer U, Haefeli T, Kappeler L, et al. Age-dependent differences in demographics, risk factors, co-morbidity, etiology, management, and clinical outcome of acute ischemic stroke. J Neurol. Epub 2008 Jul 28.

8. Adunsky A, Hershkowitz M, Rabbi R, Asher-Sivron L, Ohry A. Functional recovery in young stroke patients. Arch Phys Med Rehabil. 1992;73:859-62.

9. Neau JP, Ingrand P, Mouille-Brachet C, Rosier MP, Couderq C, Alvarez A, et al. Functional recovery and social outcome after cerebral infarction in young adults. Cerebrovasc Dis. 1998 SepOct; 8(5):296-302.

10. Tissue plasminogen activator for acute ischemic stroke. The National Institute of Neurological Disorders and Stroke rt-PA Stroke Study Group. N Engl J Med. 1995;333(24):1581-7.

11. The NINDS tPA Stroke Study Group. Generalized efficacy of t-PA for acute stroke: subgroup analysis of the NINDS t-PA stroke trial. Stroke. 1997;28:2119-25.

12. Wagner JC, Lutsep HL. Thrombolysis in young adults. J Thromb Thrombolysis. 2005;20(2):133-6.

13. Hill MD, Buchan A. Thrombolysis for acute ischemic stroke: results of the Canadian Alteplase for Stroke Effectiveness Study. CMAJ. 2005;172(10):1307-12.

14. Norris JW, Buchan A, Cote R, Hachinski V, Phillips SJ, Shuaib A, et al. Canadian guidelines for intravenous thrombolytic treatment in acute stroke. A consensus statement of the Canadian Stroke Consortium. Can J Neurol Sci. 1998 August;25(3):257-9.

15. Bamford J, Sandercock P, Dennis M, Burn J, Warlow C. A prospective study of acute cerebrovascular disease in the community: the Oxfordshire Community Stroke Project-- 198186. 2. Incidence, case fatality rates and overall outcome at one year of cerebral infarction, primary intracerebral and subarachnoid haemorrhage. J Neurol Neurosurg Psychiatry. $1990 \mathrm{Jan} ; 53(1): 16-22$

16. Barber PA, Demchuk AM, Zhang J, Buchan A. Validity and reliability of a quantitative computed tomography score in predicting outcome of hyperacute stroke before thrombolytic therapy. ASPECTS Study Group. Alberta Stroke Programme Early CT Score. Lancet. 2000 May 13;355(9216):1670-4. 
17. Biller J, Adams HP Jr, Bruno A, Love BB, Marsh EE 3rd. Mortality in acute cerebral infarction in young adults - a ten-year experience. Angiology. 1991; 42:224-30.

18. Popa-Wagner A, Carmichael ST, Kokaia Z, Kessler C, Walker LC. The response of the aged brain to stroke: too much, too soon? Curr Neurovase Res. 2007 Aug:4(3):216-27.

19. Adams HP Jr, del Zoppo G, Alberts MJ, Bhatt DL, Brass L, Furlan $A$, et al. Guidelines for the early management of adults with ischemic stroke: a guideline from the American Heart Association/American Stroke Association Stroke Council, Clinical Cardiology Council, Cardiovascular Radiology and Intervention Council, and the Atherosclerotic Peripheral Vascular Disease and Quality of Care Outcomes in Research Interdisciplinary Working Groups: The American Academy of Neurology affirms the value of this guideline as an educational tool for neurologists. Circulation. 2007 May 22;115(20): e478-534.

20. European Stroke Organization (ESO) Executive Committee, ESO Writing Committee: guidelines for management of ischaemic stroke and transient ischaemic attack 2008. Cerebrovasc Dis. 2008;25:457-507.

21. Kwan J, Hand P, Sandercock P. A systematic review of barriers to delivery of thrombolysis for acute stroke. Age Ageing. 2004 Mar;33(2):116-21.

22. Schroeder E, Rosamond WD, Morris DL, Evenson KR, Hinn AR. Determinants of use of emergency medical services in a population with stroke symptoms (DASH II). Stroke. 2000;31: 2591-6.
23. Scott P, Silbergleit R. Misdiagnosis of stroke in tissue plasminogen activator-treated patients. Ann Emerg Med. 2003;42:611-8.

24. Kittner SJ, Stern BJ, Wozniak M, Buchholz DW, Earley CJ, Feeser BR, et al. Cerebral infarction in young adults: the BaltimoreWashington Cooperative Young Stroke Study. Neurology. 1998; $50: 890-4$

25. Lindgren A, Roijer A, Norrving B, Wallin L, Eskilsson J, Johansson BB. Carotid artery and heart disease in subtypes of cerebral infarction. Stroke. 1994;25(12):2356-62.

26. Radhakrishnan K, Ashok PP, Sridharan R, Mousa ME. Stroke in the young: incidence and pattern in Benghazi, Libya. Acta Neurol Scand. 1986;73:434-8.

27. Nencini $\mathbf{P}$, Inzitari D, Baruffi MC, Fratiglioni L, Gagliardi R, Benvenuti $\mathrm{L}$, et al. Incidence of stroke in young adults in Florence, Italy. Stroke. 1988;19:977-81.

28. Guidetti D, Baratti M, Zucco RG, Greco G, Terenziani S, Vescovini $\mathrm{E}$, et al. Incidence of stroke in young adults in the Reggio Emilia area, northern Italy. Neuroepidemiology. 1993;12:82-7.

29. Leno C, Berciano J, Combarros O, Polo JM, Pascual J, Quintana F, et al. A prospective study of stroke in young adults in Cantabria, Spain. Stroke. 1993;24:792-5.

30. Jacobs BS, Boden-Albala B, Lin IF, Sacco RL. Stroke in the young in the northern Manhattan stroke study. Stroke. 2002 Dec;33 (12):2789-93 